\title{
Alloy 617 Isochronous Stress-Strain Curves
}

\author{
Jill Wright, Nancy Lybeck \\ July 2015
}

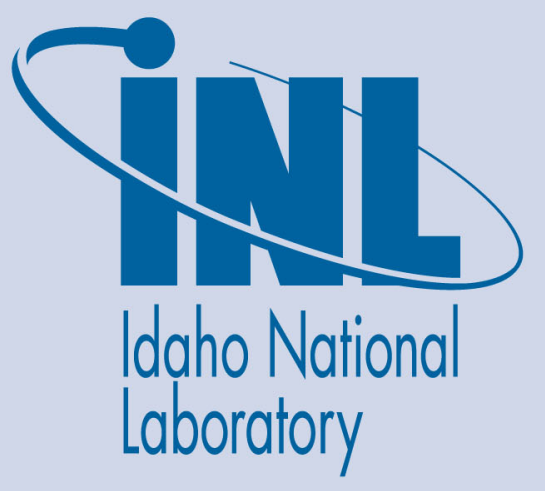

The INL is a U.S. Department of Energy National Laboratory operated by Battelle Energy Alliance 


\title{
Alloy 617 Isochronous Stress-Strain Curves
}

\author{
Jill Wright, Nancy Lybeck
}

July 2015

\section{Idaho National Laboratory Idaho Falls, Idaho 83415}

http://www.inl.gov

Prepared for the

U.S. Department of Energy

Under DOE Idaho Operations Office

Contract DE-AC07-05ID14517 


\section{Nuclear Energy}

\section{Alloy 617 Isochronous Stress-Strain Curves}

Advanced Reactor Technologies

Advanced Materials R\&D Program Review

July 14-15, 2015

Jill Wright

Nancy Lybeck 


\section{Work Package AT-15IN160101 Subtask: Isochronous Stress-Strain Curves}

Nuclear Energy

Subtask Relevancy

- Isochronous stress-strain curves are an integral part of the Code Case

- Required in applying the Subsection $\mathrm{NH}$ design procedures.

- Provide designers with strain caused by stress under elevated temperature assuming average properties

Technical Approach/Results/Accomplishments

- Developed hot tensile curves based on the INL Alloy 617 tensile data

- Fit a creep model to INL generated creep curves (up to $3 \%$ creep strain)

- Determined the stress and temperature dependence of the parametric constants in the creep model

Shifted the hot tensile and isochronous curves to represent the average behavior based on a larger data set

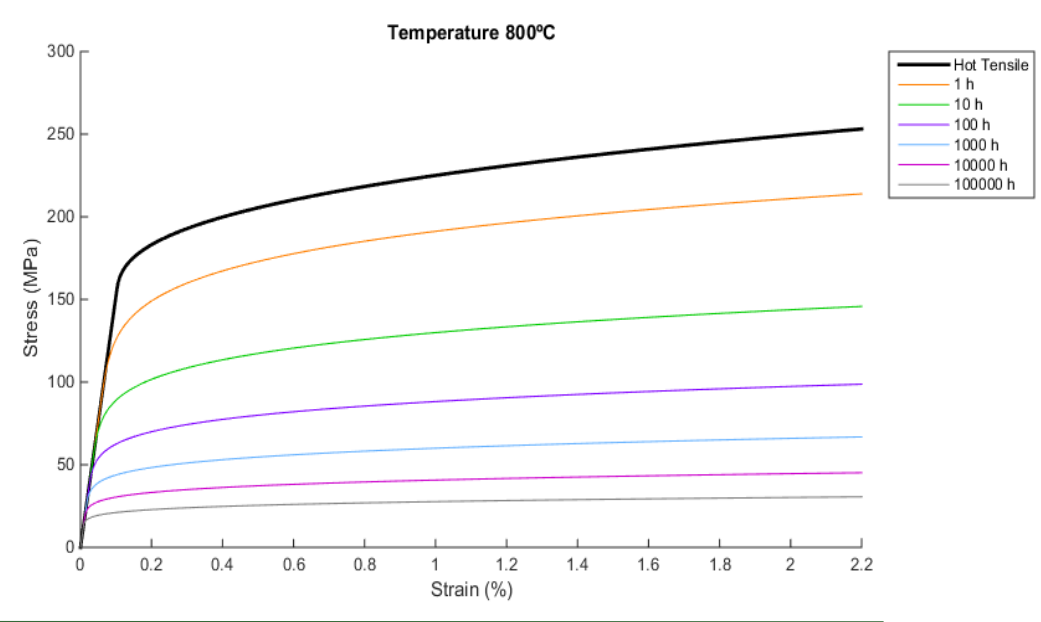

Expected Deliverable \& Schedule

- Contribute to Appendix T of the Alloy 617 Code Case

- Draft Code Case to be completed August 31, 2015 


\section{Introduction}

- Isochronous stress-strain curves (ISSC) and hot tensile curves are needed up to $2.2 \%$ strain for Alloy 617

$-427-950^{\circ} \mathrm{C}$ in $25^{\circ} \mathrm{C}$ increments

- $800-1800^{\circ} \mathrm{F}$ in $50^{\circ} \mathrm{F}$ increments

- Hot tensile curves provide an upper bound for isochronous stressstrain curves

- Isochronous curves are not needed for temperature ranges where creep is negligible 


\section{HOT TENSILE CURVES}




\section{What is a Hot Tensile Curve?}

- Hot tensile curves represent tensile behavior of an average strength heat of the alloy for various temperatures

Experimental tensile curves are used to match the shape

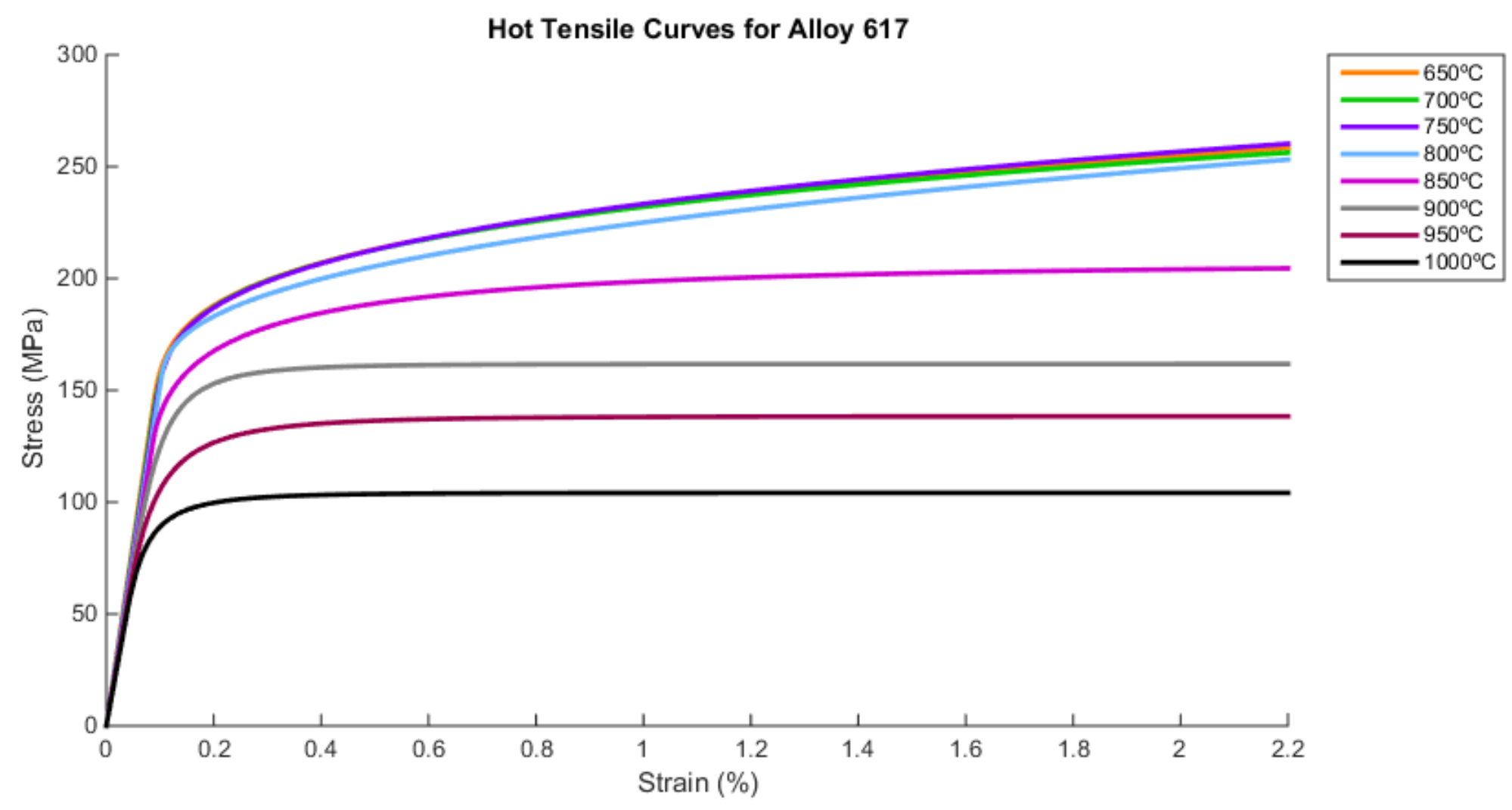




\section{Hot Tensile Curves: Ramberg-Osgood}

Used for lower temperatures where creep is not significant

$$
\begin{gathered}
\varepsilon=\varepsilon_{E}+\varepsilon_{p} \\
\varepsilon_{E}=\frac{\sigma}{E} \\
\varepsilon_{p}=a\left(\sigma-\sigma_{L}\right)^{m} \quad \sigma>\sigma_{L}
\end{gathered}
$$

$\varepsilon=$ strain

$\sigma=$ stress

$E=$ elastic modulus

$\sigma_{L}=$ proportional limit

- The parameters $a$ and $m$ are chosen so the curve goes through the experimentally determined $0.2 \%$ offset yield strength and the $2 \%$ offset flow stress for the specified temperature. 


\section{Hot Tensile Curves: Voce}

Used for higher temperatures where creep is significant

$$
\begin{aligned}
& \varepsilon=\varepsilon_{E}+\varepsilon_{p} \\
& \varepsilon_{E}=\frac{\sigma}{E} \\
& \varepsilon_{p}=\frac{1}{b}\left[\ln \left(\frac{\sigma_{L}-\sigma_{U T S}}{\sigma-\sigma_{U T S}}\right)\right]^{2} \quad \sigma>\sigma_{L}
\end{aligned}
$$

$\varepsilon=$ strain$$
\sigma=\text { stress }
$$$$
\sigma_{U T S}=\text { ultimate tensile strength }
$$$$
\sigma_{L}=\text { proportional limit }
$$

The parameter $b$ is chosen so the curve goes through the experimentally determined $0.2 \%$ offset yield. 


\section{$650^{\circ} \mathrm{C}$ Hot Tensile Curve}

\section{Nuclear Energy}

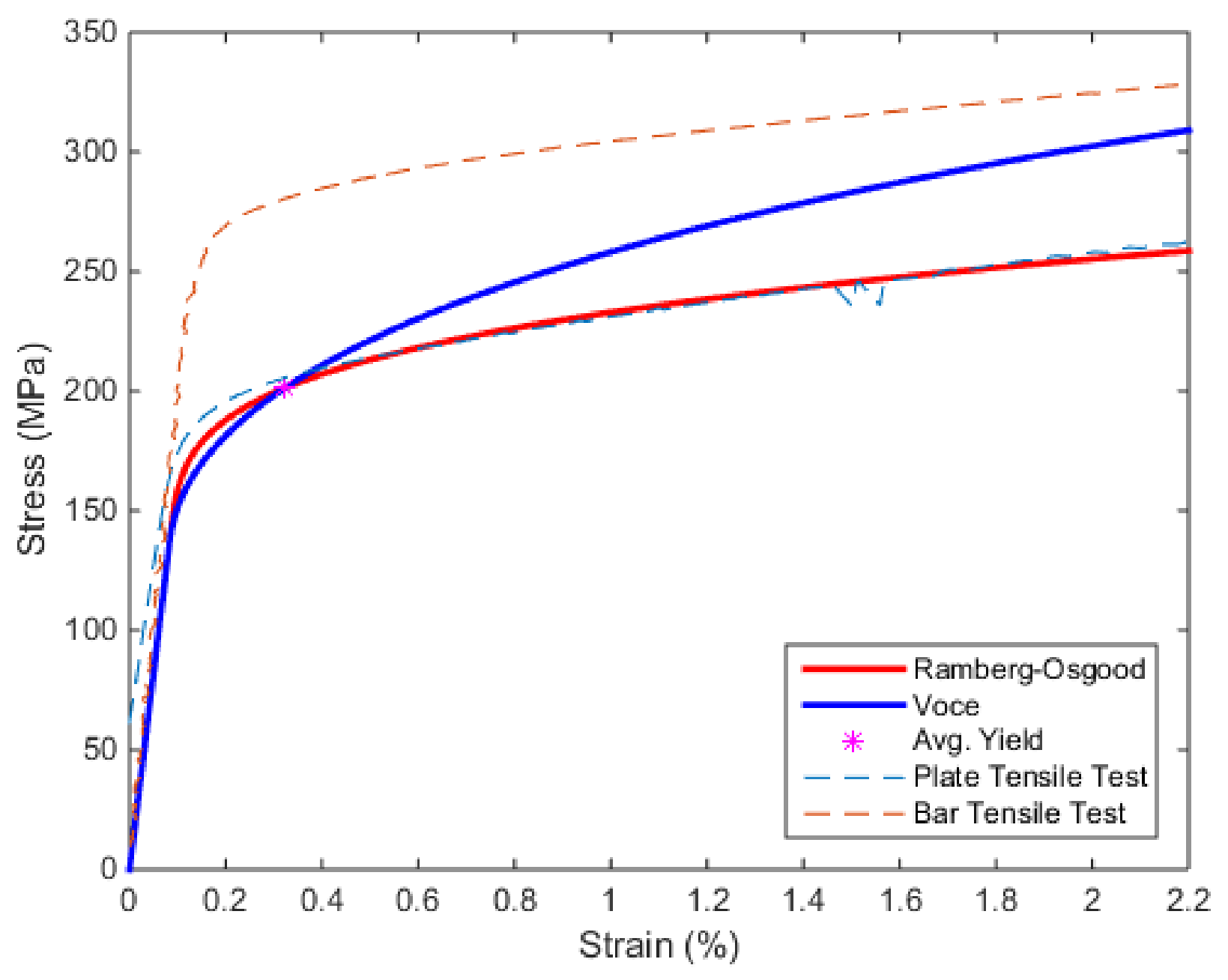




\section{$800^{\circ} \mathrm{C}$ Hot Tensile Curve}

\section{Nuclear Energy}

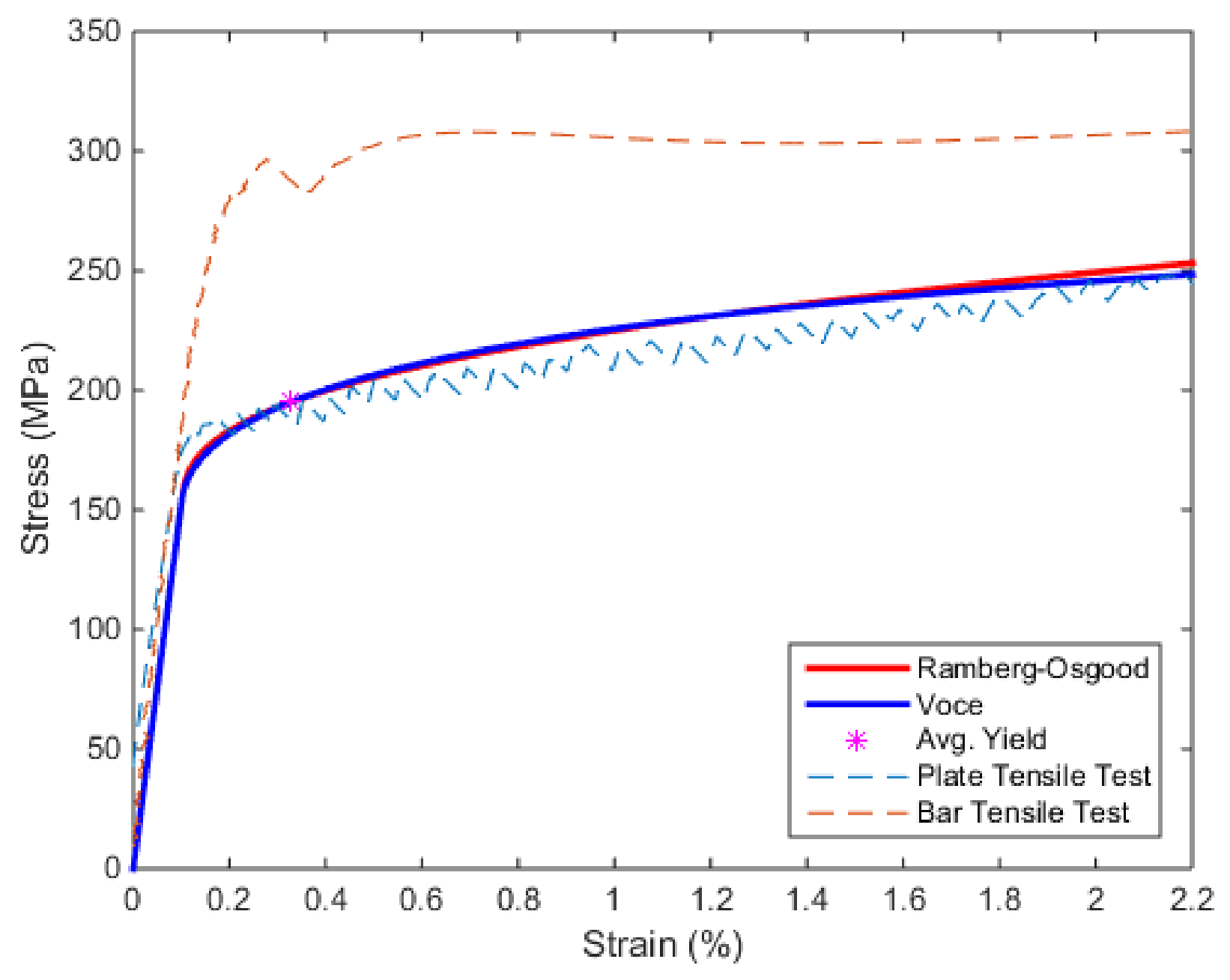




\section{$950^{\circ} \mathrm{C}$ Hot Tensile Curve}

\section{Nuclear Energy}

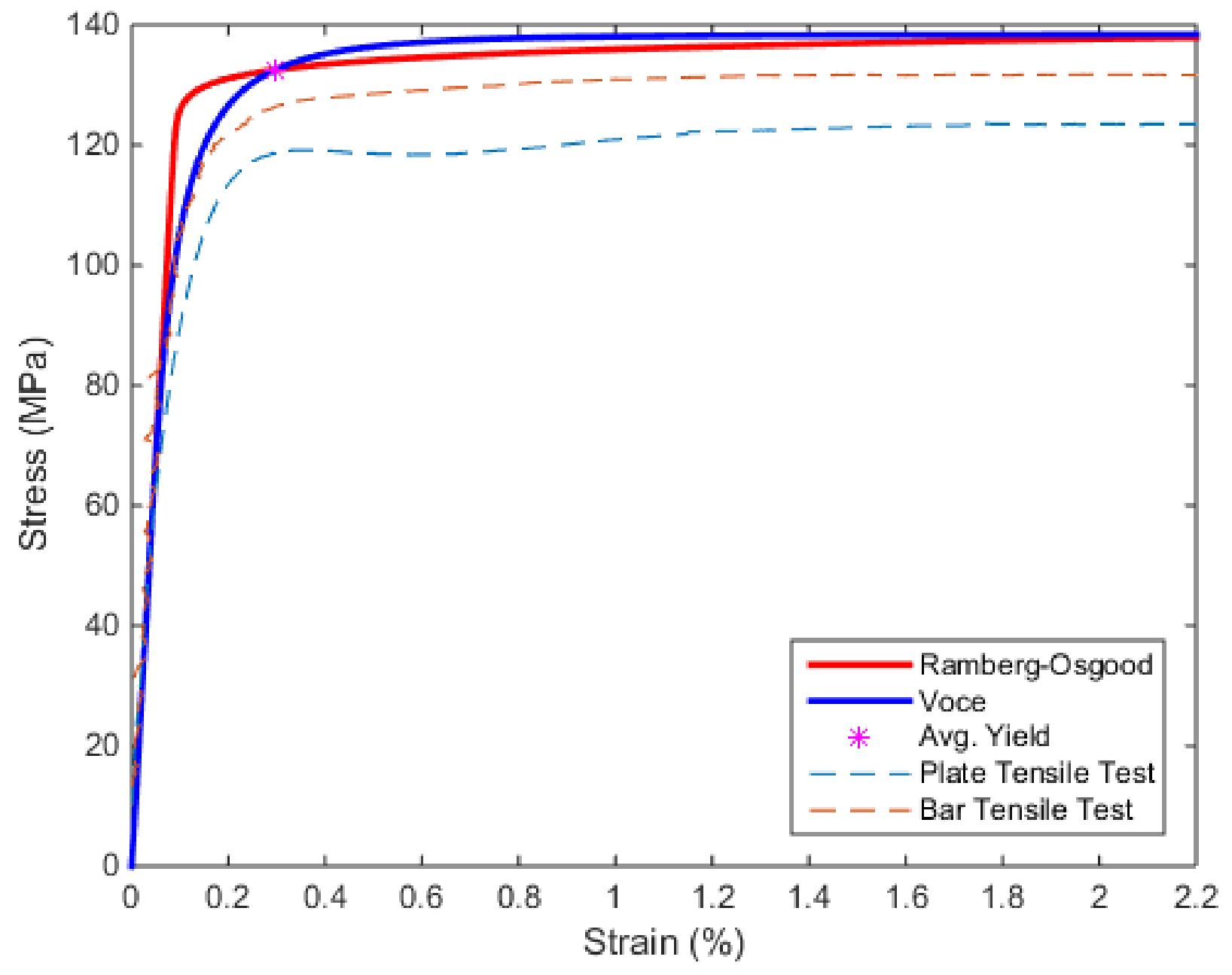




\section{What is an Isochronous Stress Strain Curve?}

- Isochronous curves are constant-time stress-strain curves for a given temperature
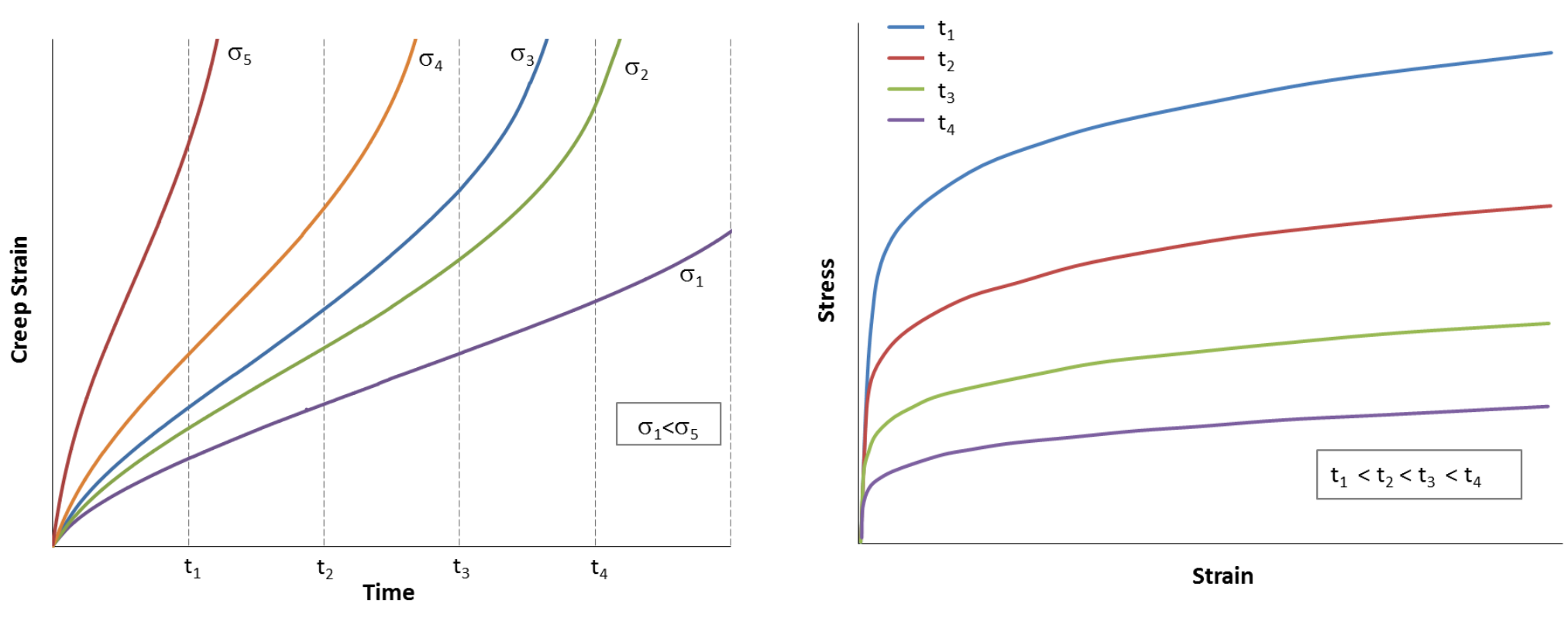
The creep strain equation selected has been used by Swindeman (1998) and Booker (1990)

$$
\varepsilon_{c}=a t^{1 / 3}+\operatorname{mcr} t
$$

$a=$ primary creep strain constant mcr $=$ minimum creep rate

- The equation was fit to all INL creep curves up to $3 \%$ strain for temperatures $\geq 800^{\circ} \mathrm{C}$

The $750^{\circ} \mathrm{C}$ creep curves entered tertiary creep too quickly, and the model did not provide a good fit to the data

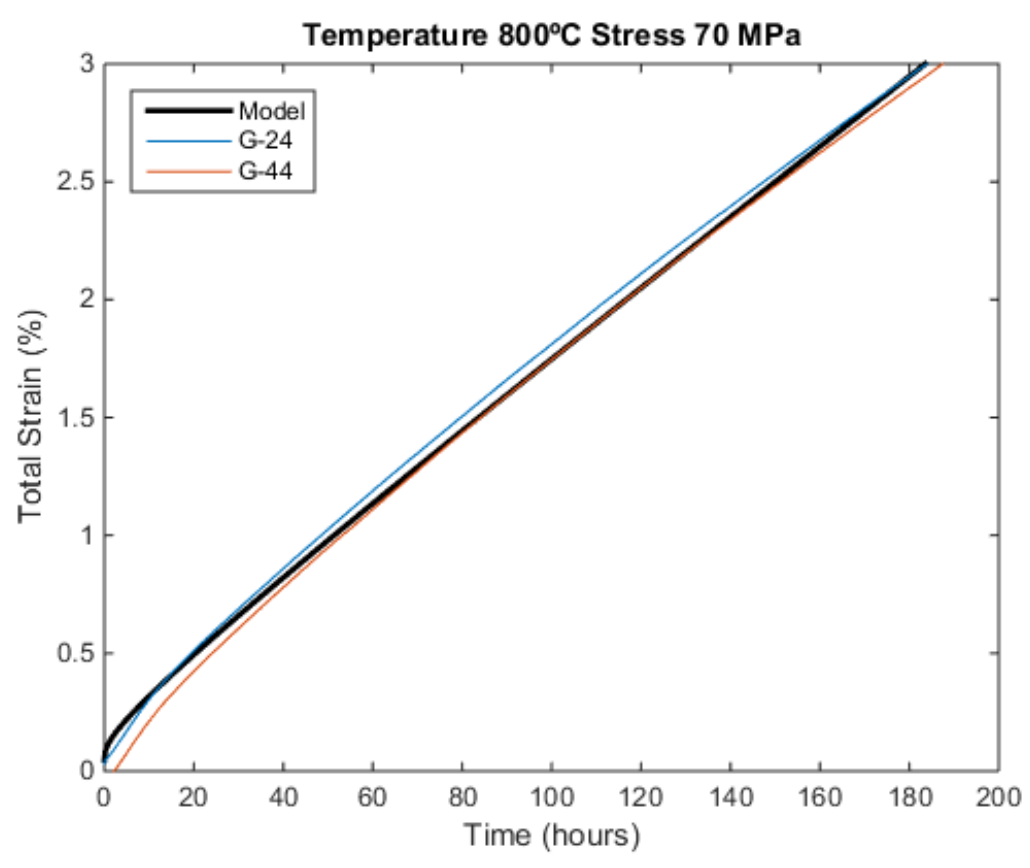




\section{Parametric Model}

Based on these results, the stress and temperature dependence of the minimum creep rate was determined using the equation

$$
m c r=a\left(\frac{\sigma}{E}\right)^{b} e^{-c / R T}
$$

$\sigma=$ stress

$E=$ elastic modulus

$R=$ universal gas constant

$T=$ absolute temperature

$a, b$, and c are determined optimally

The stress and temperature dependence of the primary creep strain constant was quantified using the same equation form

- The isochronous curves can then be generated for each time/temperature combination

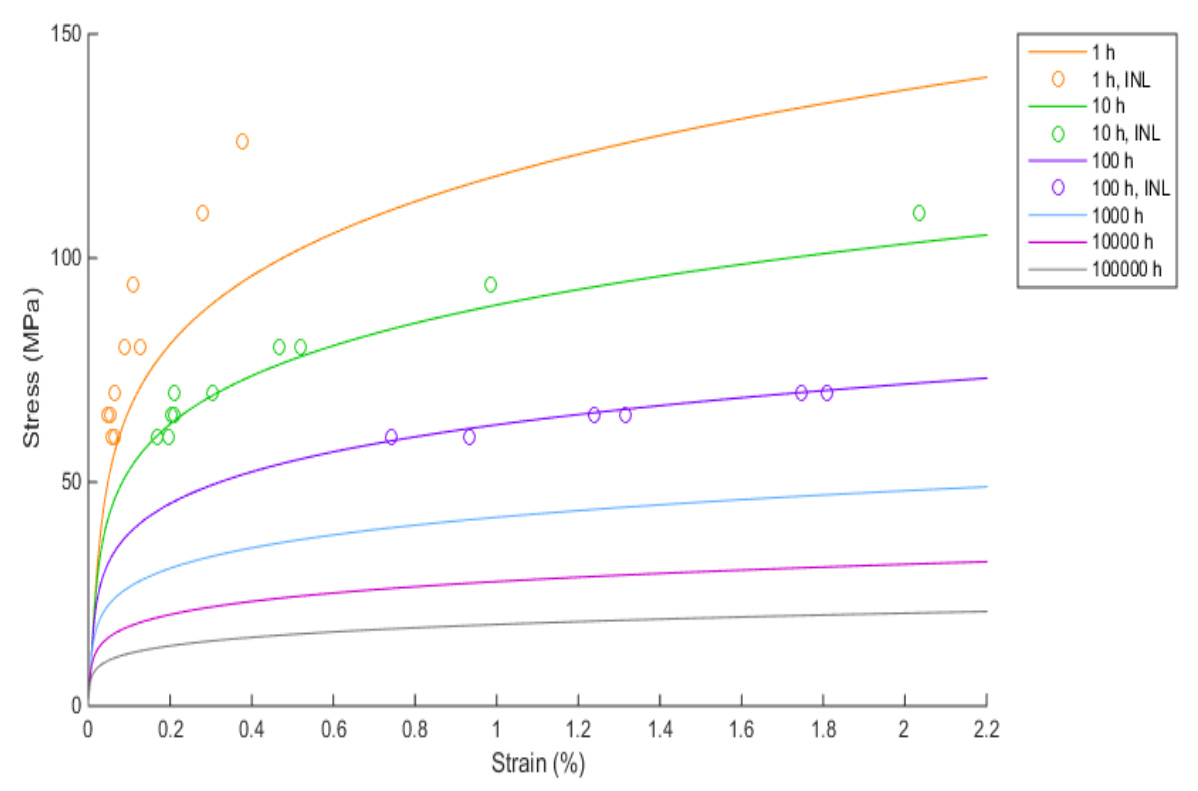

14 


\section{Shifting Isochronous Curves}

Nuclear Energy

Generate isochronous curves for the INL heat of Alloy 617

- Calculate the average stress value at $1 \%$ strain using the LarsonMiller equation for time to $1 \%$ strain (based on multiple heats)

$\boldsymbol{L M P}=35663.0735-6388.5288 \log _{10}(\sigma)$

$$
\log _{10}\left(t_{1 \%}\right)=\frac{L M P}{T}-19.64334
$$

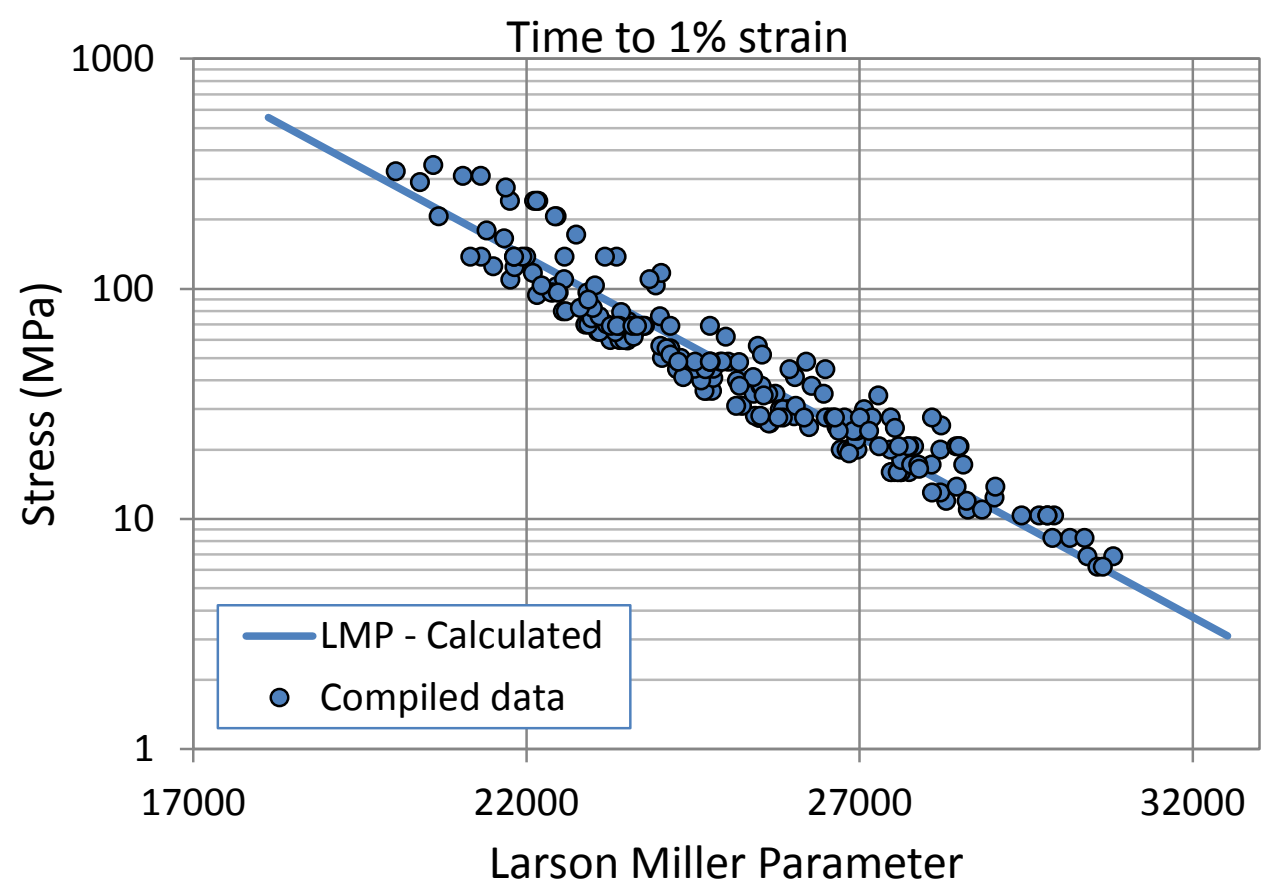




\section{Shifting Isochronous Curves}

Nuclear Energy

- Shift the isochronous curves along the elastic stress-strain curve to go through the average stress value at $1 \%$ strain

Exclude curves that exceed the hot tensile curve in the $2 \%$ strain range

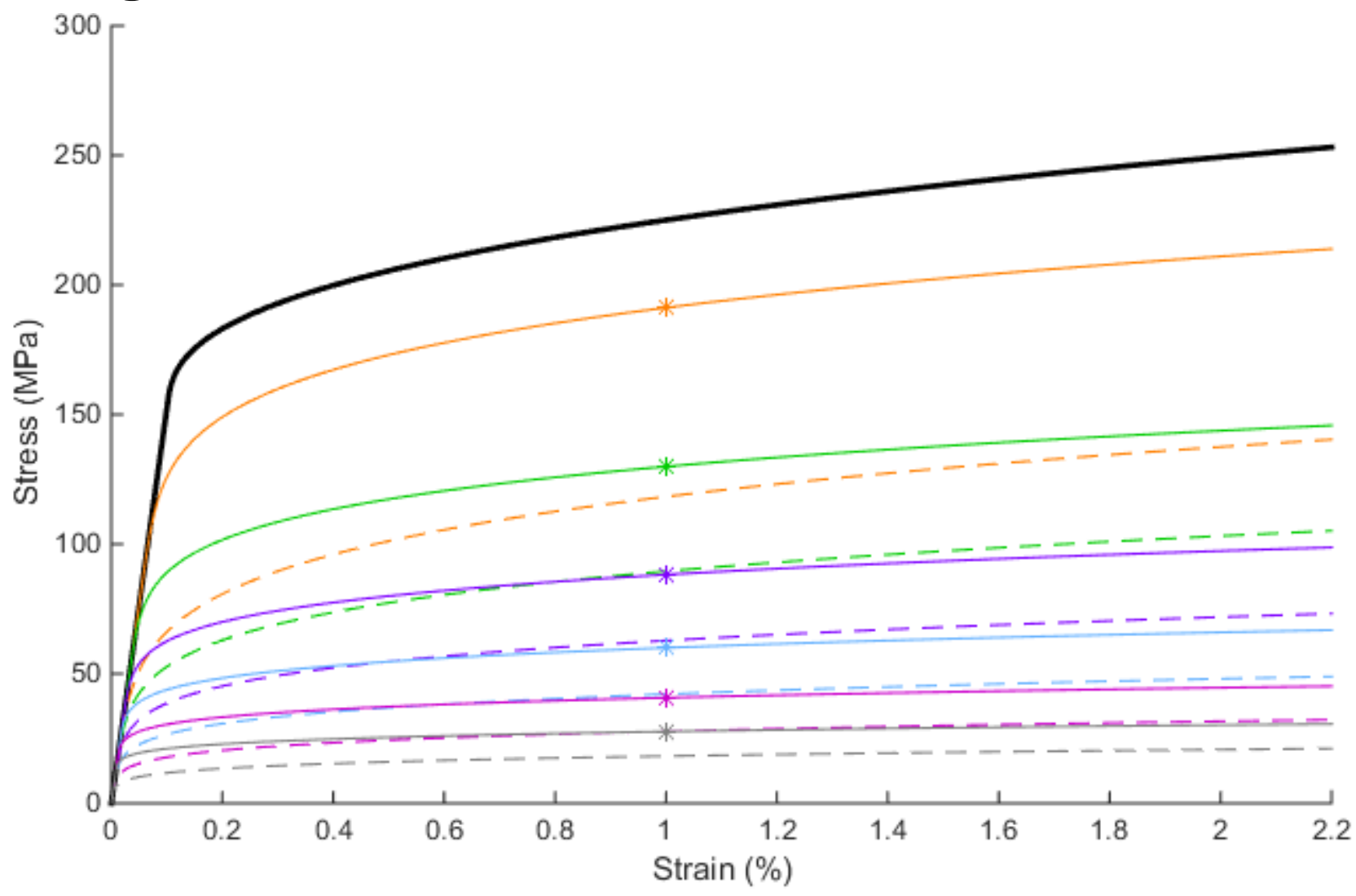

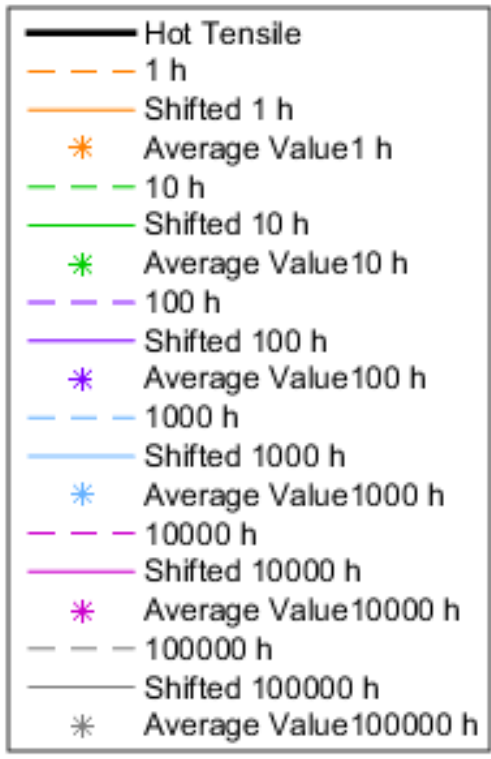




\section{Comparing Isochronous Curves}

Nuclear Energy

- German Isochronous Stress Strain Curves
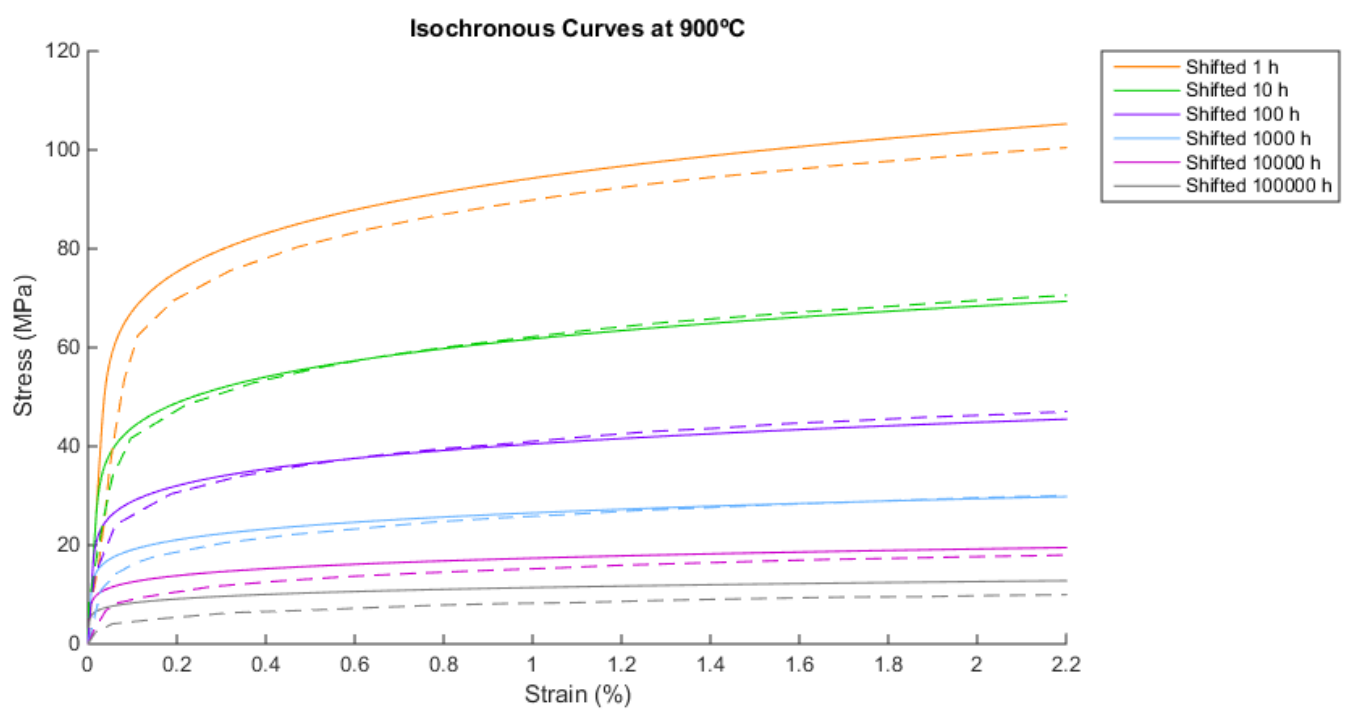

1990s Draft Code Case
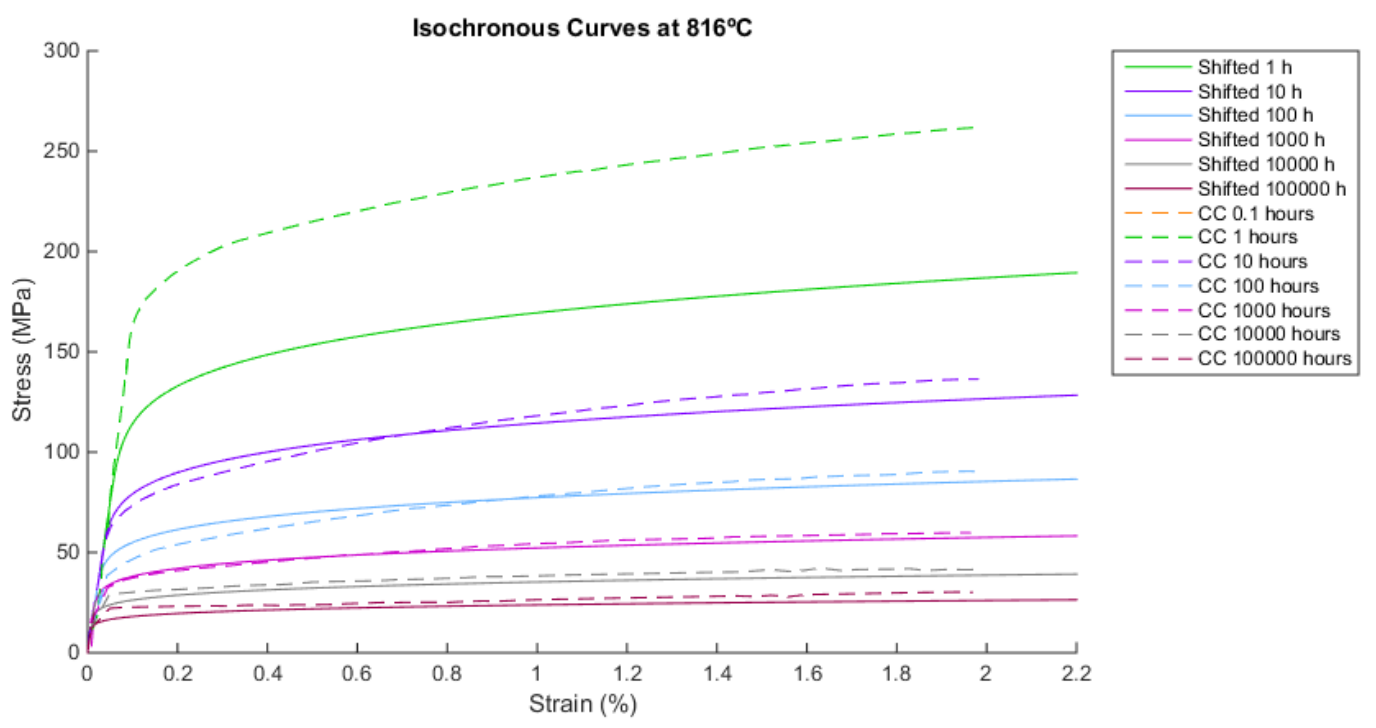


\section{PROPOSED APPENDIX T FIGURES}




\section{$650^{\circ} \mathrm{C}$ Results}

\section{Nuclear Energy}

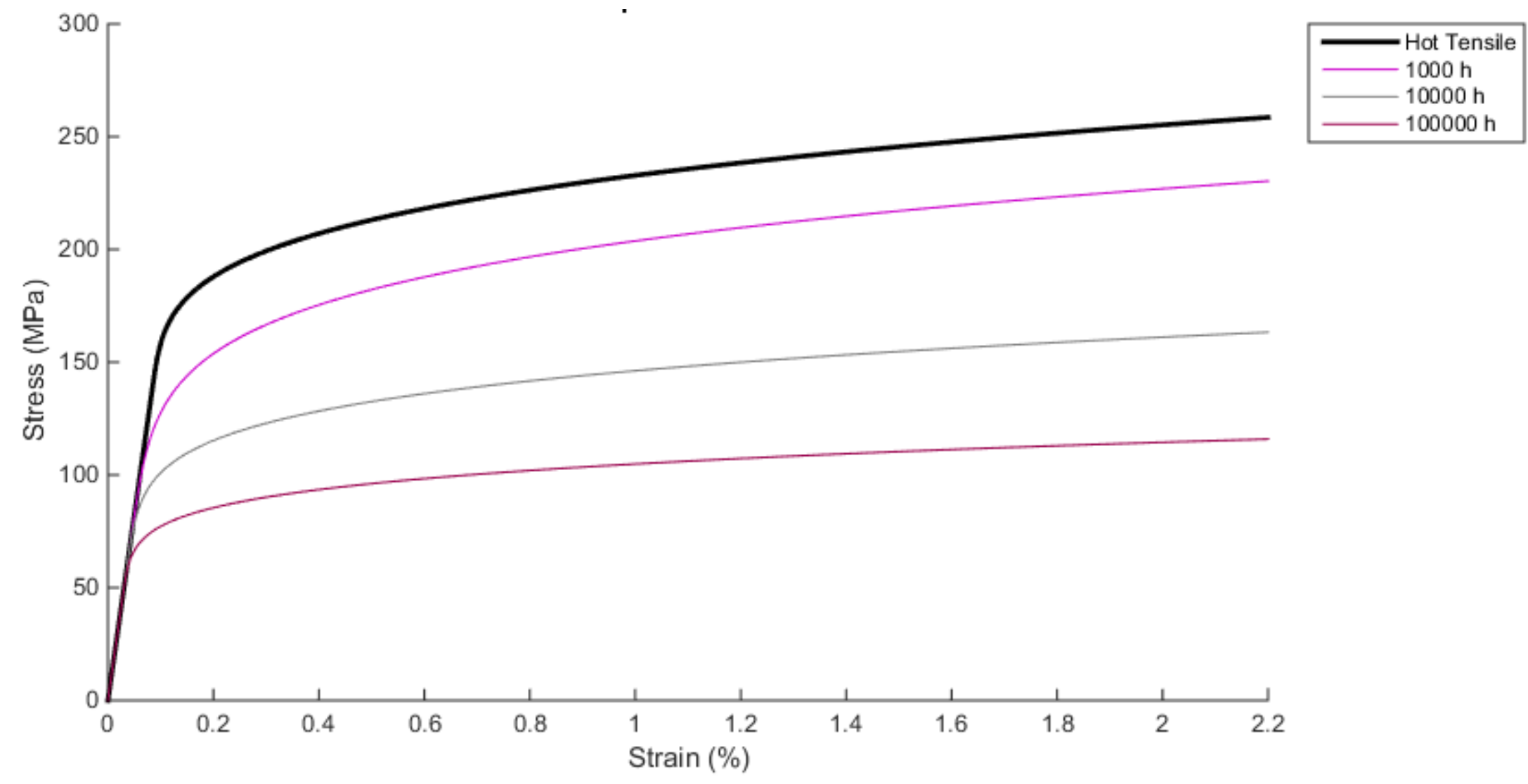




\section{$800^{\circ} \mathrm{C}$ Results}

\section{Nuclear Energy}

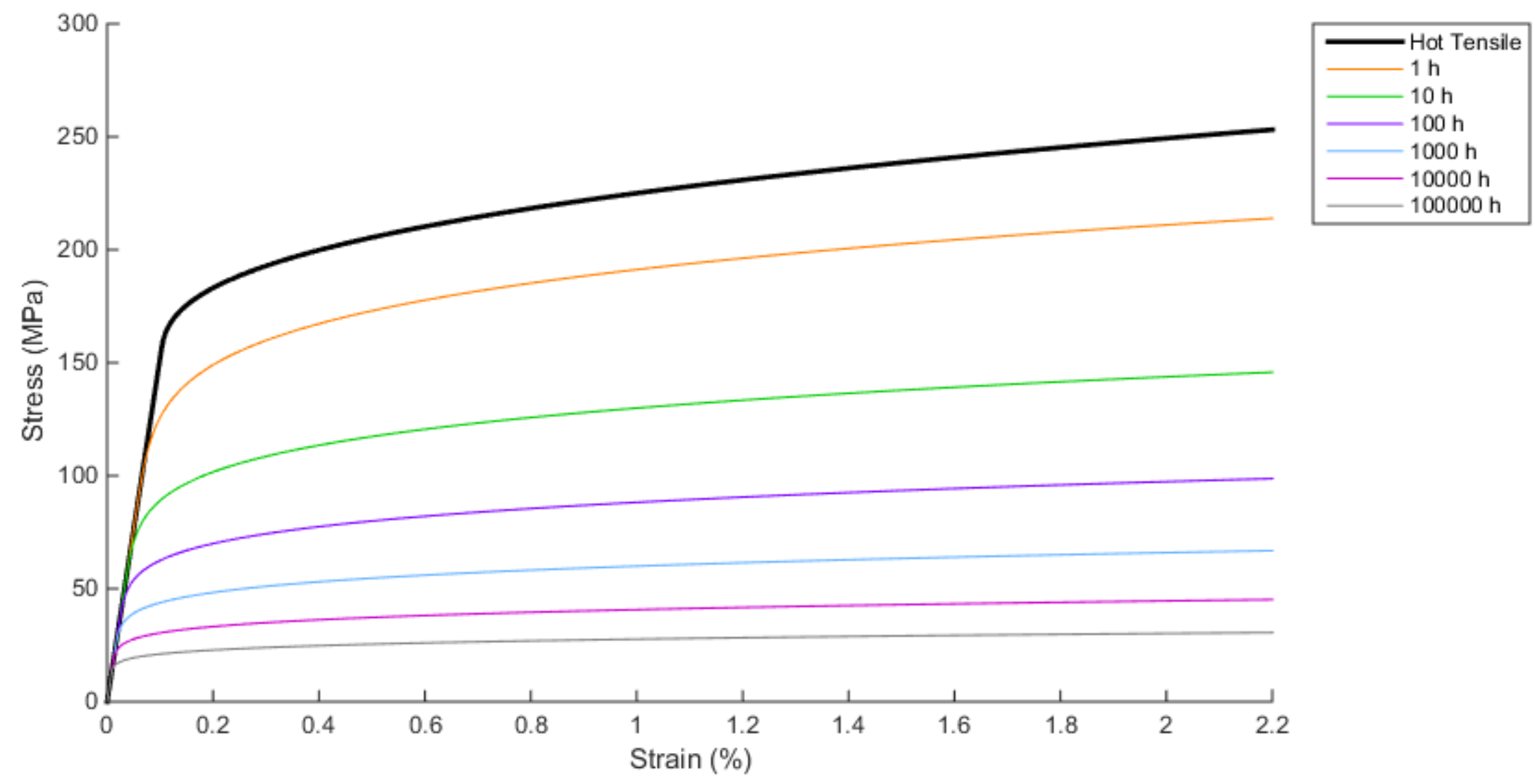




\section{$950^{\circ} \mathrm{C}$ Results}

Nuclear Energy

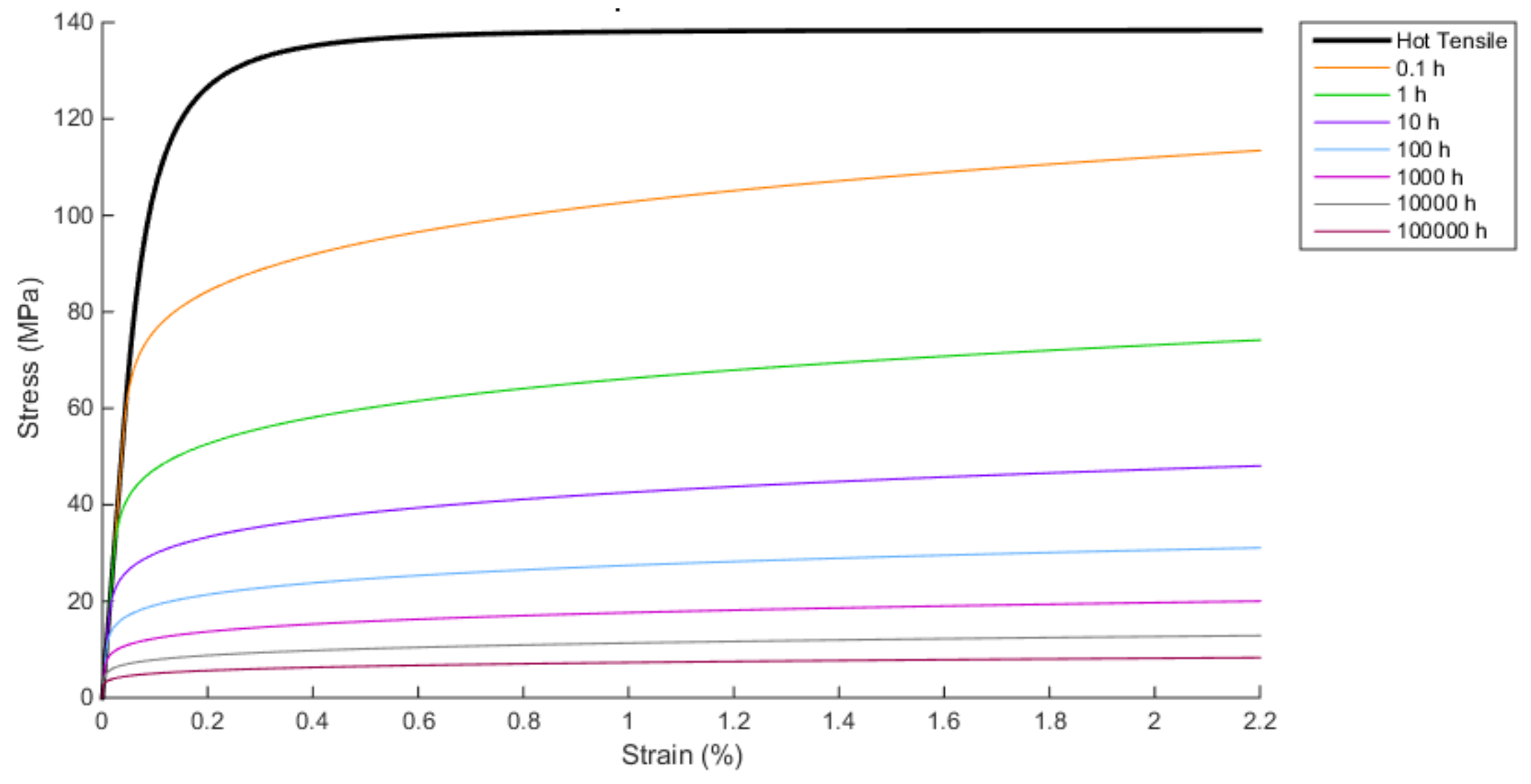




\section{0 hour Results}

Nuclear Energy

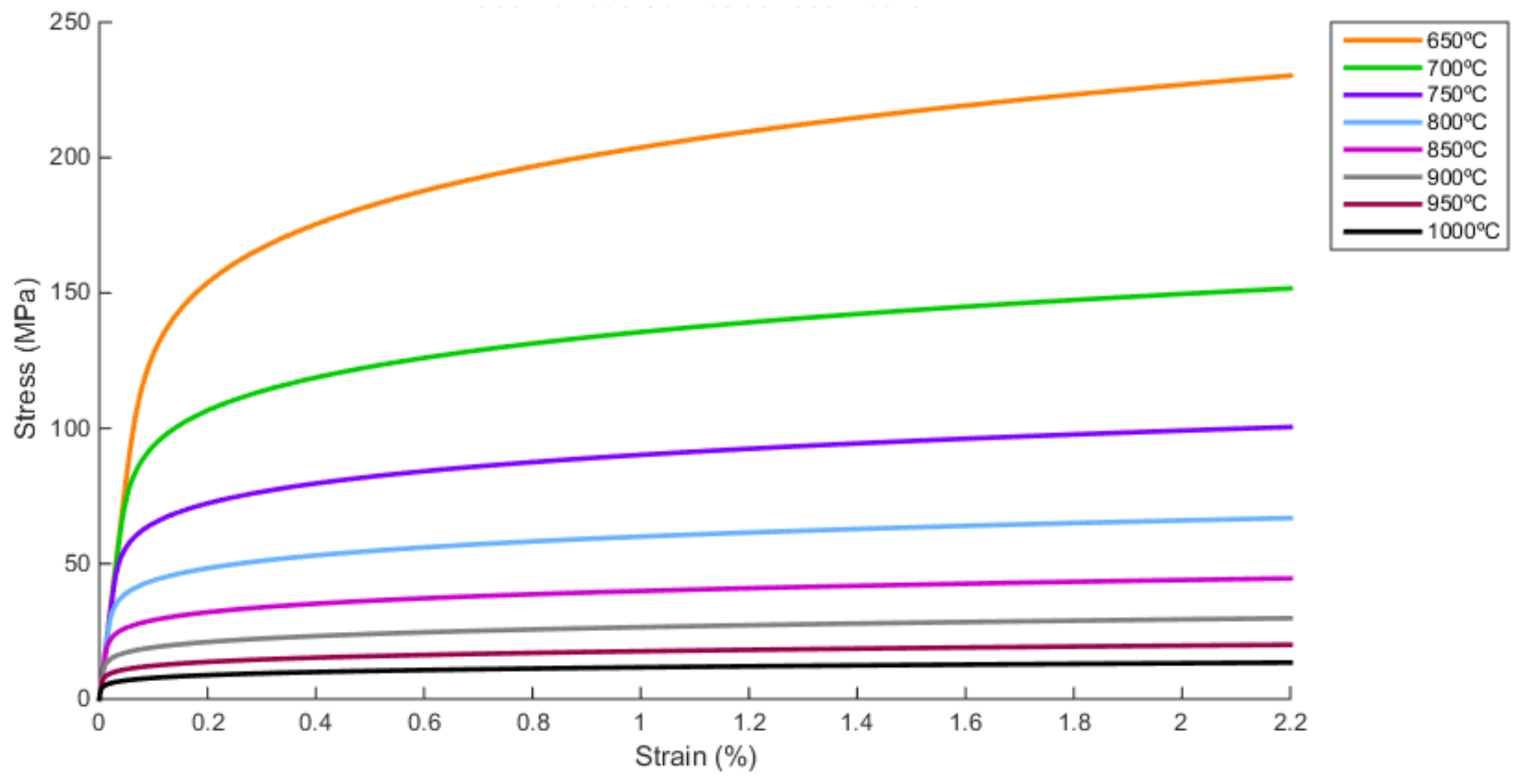


- Hot tensile curves were generated

- Ramberg-Osgood equation from $650-800^{\circ} \mathrm{C}$

- Voce equation above $800^{\circ} \mathrm{C}$

- The curves were shifted to reflect the average behavior of Alloy 617

- Isochronous curves were generated from $650-1000^{\circ} \mathrm{C}$

- 2-parameter creep strain model was used

- The curves were shifted to reflect the average behavior of Alloy 617 at $1 \%$ strain

- Work will continue

- Refine curves as needed

- Generate curves for conventional units

- Develop curves for lower temperatures where ISSC are required but no creep data is available 